\title{
Correction to: Novel Cooperative Controller Design of Heterogeneous Energy Storages for Economic Applications in Electric Railway Systems
}

\author{
Hansang Lee ${ }^{1}$. Jaewon $\mathrm{Kim}^{2} \cdot$ Changmu Lee ${ }^{2}$. Joorak Kim² \\ Published online: 24 March 2020 \\ (C) The Korean Institute of Electrical Engineers 2020

\section{Correction to: \\ Journal of Electrical Engineering \& Technology (2020) 15:979-987 \\ https://doi.org/10.1007/s42835-019-00341-4} \\ Publisher's Note Springer Nature remains neutral with regard to \\ jurisdictional claims in published maps and institutional affiliations.
}

Unfortunately the acknowledgement section has been omitted during the e.proof reading:

Acknowledgements This research was funded by the Ministry of Land, Infrastructure and Transport's Railway Technology Research Project, "Development of Real Time Simulator and Analysis Model for Railway Power System (19RTRP-B146034-02)"

The authors apologise this mistake.

The original article can be found online at https://doi.org/10.1007/ s42835-019-00341-4.

Joorak Kim

jrkim@krri.re.kr

Hansang Lee

hslee@semyung.ac.kr

Jaewon Kim

youngkjw@krri.re.kr

Changmu Lee

cmlee@krri.re.kr

1 Semyung University, Jecheon, South Korea

2 Korea Railroad Research Institute, Uiwang, South Korea 